\title{
Faecal occult blood screening reduced the incidence of colorectal cancer
}

Mandel JS, Church TR, Bond JH, et al. The effect of fecal occult-blood screening on the incidence of colorectal cancer. N Engl J Med 2000 Nov 30;343:1603-7.

\section{QUESTION: Does faecal occult blood screening reduce the incidence of colorectal cancer?}

\section{Design}

Randomised \{allocation concealed*\}†, unblinded, ${ }^{*}$ controlled trial with 18 years follow up.

\section{Setting}

Minnesota, USA.

\section{Participants}

46551 participants who were $50-80$ years of age (52\% women) and did not have a previous diagnosis of colorectal cancer. Follow up for vital status was $91 \%$ at 18 years.

\section{Intervention}

Participants were allocated to annual screening $(\mathrm{n}=15$ $532)$, biennial screening $(\mathrm{n}=15550)$, or usual care $(\mathrm{n}=15$ 363). For each screening, which was done from 1976-82 and from 1986-92, participants prepared 2 guaiac impregnated paper slides for each of 3 consecutive stools. The mean rate of compliance was $75 \%$ in the annual screening group and $78 \%$ in the biennial screening group. Participants with $\geqslant 1$ positive slide had a diagnostic evaluation, which included history taking, physical examination, single column barium enema (discontinued in 1978), rigid proctosigmoidoscopy (discontinued in 1982), urinalysis, complete blood count, routine blood chemistry tests, upper gastrointestinal radiographic series (discontinued in 1982), chest radiography, electrocardiography, and colonoscopy.

\section{Main outcome measure}

Incidence of colorectal cancer.

\section{Main results}

1359 new cases of colorectal cancer were diagnosed: 417 in the annual screening group, 435 in the biennial screening group, and 507 in the usual care group. The ratios of the cumulative incidence rates in the screening groups relative to the usual care group were $0.80(95 \%$ CI 0.70 to 0.90 ) for annual screening and 0.83 (CI 0.73 to 0.94 ) for biennial screening. The predictive values for colorectal cancer for positive test results ranged from $0.87 \%$ (CI $0.59 \%$ to $1.29 \%$ ) for a single test in the annual screening group to $6.13 \%$ (CI $4.56 \%$ to $8.20 \%$ ) in the biennial screening group.

\section{Conclusion}

Annual or biennial faecal occult blood screening reduced the incidence of colorectal cancer.

*See glossary.

$\dagger$ Information provided by author.

\section{COMMENTARY}

Three large randomised trials have convincingly shown that faecal occult blood testing can reduce mortality from colorectal cancer, presumably by detecting cancers in surgically curable stages. ${ }^{1-4}$ The study by Mandel $e t a l$ is the first definitive proof that screening can also decrease the incidence of colorectal cancer.

The authors enrolled 46551 patients between 1975 and 1978 and randomly allocated them to annual or biennial faecal occult blood screening or to a control group. The screened groups developed about $20 \%$ fewer cancers; the reduction in incidence was similar in the annual and biennial screening groups. The study also found that although people who had more positive test results were more likely to have either a colorectal cancer or a large adenoma, the predictive value of a positive test result was $<8 \%$ in the annual screening group. Faecal occult blood testing was an imperfect test.

This study is important. It tells us for the first time that faecal occult blood screening can decrease both the incidence of cancer and the mortality rate. The incidence reduction is relatively modest. After 18 years of follow up, the cumulative incidence of cancer was 39 per 1000 people in the control group compared with 32 per 1000 people in the annual screening group. Admittedly, the results probably underestimate the potential reduction in cancer incidence because compliance with screening was not complete and some participants in the control group were screened. The study was designed to evaluate the benefits of screening but not the costs.

It is logical to conclude that the reduction in incidence resulted from removal of adenomas by colonoscopy, which validates the hypothesis that carcinomas arise from adenomas. This study therefore provides indirect scientific support for the benefits of colonoscopy to prevent colorectal cancer

The good news for clinicians and patients is that faecal occult blood screening prevents colorectal cancer. Conscientious application of this screening test could save lives.

Melissa M Rich, MD Robert S Sandler, MD, MPH University of North Carolina at Chapel Hill Chapel Hill, North Carolina, USA

1 Mandel JS, Church TR, Ederer F, et al. Colorectal cancer mortality: effectiveness of biennial screening for fecal occult blood. J Natl Cancer Inst 1999;91:434-7.

2 Kronberg O, Fenger C, Olsen J, et al. Randomised study of screening for colorectal cancer with faecal-occult-blood test. Lancet 1996;348:1467-71.

3 Hardcastle JD, Chamberlain JO, Robinson MH, et al. Randomised controlled trial of faecal-occult-blood screening for colorectal cancer. Lancet 1996;348:1472-74.

4 Mandel JS, Bond JH, Church TR, et al. Reducing mortality from colorectal cancer by screening for fecal occult blood. Minnesota colon cancer control study. $N$ Engl J Med 1993;328:1365-71.

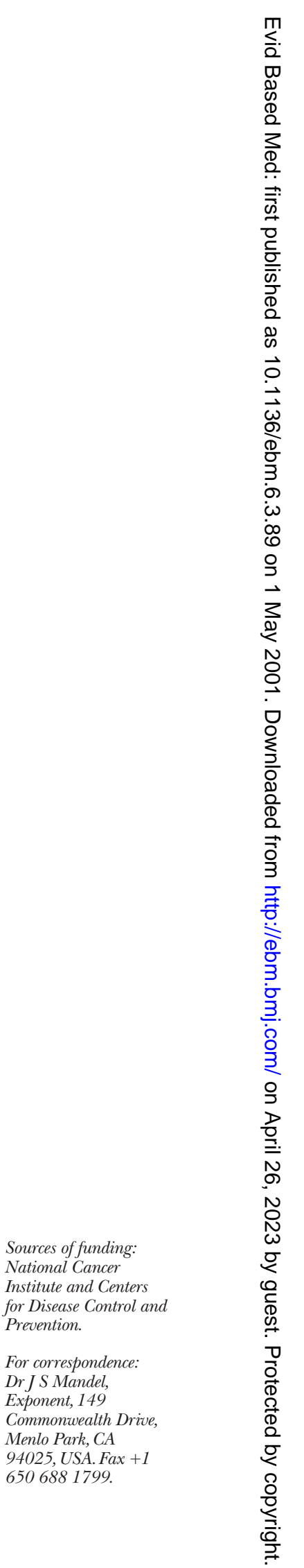

Sources of funding: Institute and Centers for Disease Control and Prevention.

For correspondence: Dr J S Mandel, Commonwealth Drive, Menlo Park, CA 94025, USA. Fax +1 6506881799 